\title{
A kinematic campaign to evaluate EGNOS 1046 Maritime Service
}

\author{
Deimos Ibáñez Segura, Adria Rovira Garcia, Jaume Sanz, José Miguel Juan, Guillermo González Casado, María Teresa Alonso \\ Research group of Astronomy and Geomatics, Universitat Politècnica de Catalunya, Barcelona, Spain \\ José A. López Salcedo \\ Signal Processing for Communications \& Navigation, Universitat Autònoma de Barcelona, Bellaterra, Spain \\ Huamin Jia \\ School of Aerospace, Transport \& Manufacturing, Cranfield University, Cranfield, United Kingdom \\ Francisco Javier Pancorbo Garcia, Carlos Garcia Daroca, Irene Martin Calle, Santos Rodrigo Abadía Heredia \\ Aerospace and Defense, EVERIS, Madrid, Spain \\ Manuel López Martínez \\ Market Development, European GNSS Agency, Prague, Czech Republic
}

\section{BIOGRAPHIES}

Deimos Ibañez Segura is a research engineer at the Research Group of Astronomy and Geomatics (gAGE) from the Technical University of Catalonia (UPC). He co-authors 2 journal articles and 14 works in international meeting proceedings. He is the responsible for the upgrades of the ESA/UPC gLAB tool suite (gLAB), including ionospheric and tropospheric models and SBAS processing. He is currently developing a global monitoring system for the performance assessment of EGNOS and Signal in Space (SIS) anomaly investigation for Feared Events activities.

Adrià Rovira-Garcia is a post-doctoral researcher at UPC with a Marie Sklodowska Curie Individual Fellow titled "High Accuracy Navigation under Scintillation Conditions (NAVSCIN)". He co-authors 11 papers in peer-reviewed journals, two book chapters and over 25 works in meeting proceedings, with one best presentation award from the US Institute of Navigation and one Outstanding Poster Award from the European Geosciences Union.

Jaume Sanz is with the Department of Mathematics (UPC) and member of gAGE since 1988. He has published over 70 papers in peer-reviewed journals and more than 200 works in meeting proceedings related with GNSS, with four best paper awards from the U.S. Institute of Navigation. He is a coauthor of five patents on GNSS and four books on GNSS Data Processing.

José Miguel Juan is with the Department of Physics (UPC) and member of gAGE since 1988. He has published over 70 papers in peer-reviewed journals and more than 200 works in Meeting proceedings related with GNSS, with four best paper awards from the US Institute of Navigation. He is a coauthor of five patents on GNSS and four books on GNSS Data Processing.

Guillermo González-Casado is with the Department of Mathematics (UPC) and a member of gAGE since 2009. His research interests are focused on ionospheric modeling based on GNSS and radio occultations, Ground and satellite-based Augmentation Systems, and the study and development of GNSS applications for the study of the ionosphere and plasmasphere.

María Teresa Alonso is senior research mathematician in gAGE/UPC. She holds Master of research in Astronomy and Geodesy, in ESAC (European Space Astronomy Center). She is giving support to the GNSS projects.

José A. López Salcedo is an associate professor at the Department of Telecommunications and Systems Engineering, Universitat Autònoma de Barcelona (UAB) and member of the Signal Processing for Communications and Navigation (SPCOMNAV) research group. He has been the principal investigator of 20 research projects, most of them in the field of signal processing for GNSS receivers, coauthor of 100 papers in international conferences and 30 works in peer-reviewed journals. 
Huamin Jia is a senior lecturer of Avionics Systems at Cranfield University. Dr Jia's research interests are concerned with data fusion methodologies for integrated flight management guidance and navigation systems, trajectory optimization, UAV detect and avoid systems, fault diagnosis and prognosis, and avionics system safety assessment.

Francisco Javier Pancorbo Garcia, has an M.Sc degree in Electronic and Management Engineering from Universidad Politécnica de Madrid (1997). He is a Program Manager at everis Aeroespace and Defense, in charge of the GNSS and Earth Observation areas. He co-authors 1 journal article related to commissioning of Large Telescopes (SPIE 2007).

Carlos Garcia Daroca has a M.Sc degree in Aeroespace Engineering from Universidad Politécnica de Madrid (2014). He is senior system engineer at everis Aeroespace \& Defense with key interest in develop and deliver new or improved solutions across the entire air transport management ecosystem and its supporting technologies, focus on the safe and efficient integration of unmanned aviation.

Irene Martin Calle is a telecommunications engineer from the University of Granada (UGR) and she is currently studying Master in telecommunication engineering at Autonomous University of Madrid (UAM). She is an assistant engineer at everis Aerospace \& Defense and she provides support on the area of GNSS.

Santos Rodrigo Abadía Heredia has a B.Sc degree in Mathematics from Universidad Autónoma de Madrid (2018). He is an assistant engineer at everis Aerospace and Defense focused on the development of algorithms in the field of geometry and statistics to guarantee the safe integration of unmanned aviation.

Manuel López Martínez is Technology Officer in the European GNSS Agency (GSA), where he is supporting and fostering the adoption of Galileo and EGNOS in maritime, inland waterways and search and rescue applications. He received his PhD in System Engineering and Automation from the University of Seville in 2005, where he obtained permanent position as associate professor at in 2008. He was teaching until he joined the GSA in 2013 as seconded national expert in the Market Development Department.

\begin{abstract}
Global Navigation Satellite Systems (GNSSs) have improved the efficiency and accuracy of transportation means. In terms of safety, the European Geostationary Navigation Overlay System (EGNOS) is providing vertical and lateral guidance to civil aviation since 2011. Furthermore, EGNOS can support applications in other sectors such as maritime, railways and road.

The present contribution aims to assess the use of EGNOS for maritime navigation compliant with the International Maritime Organization (IMO) requirements established in its Resolution A.1046 (27) for harbour entrances, harbour approaches and coastal waters: $99.8 \%$ of Signal Availability, $99.8 \%$ of Service Availability, $99.97 \%$ of Service Continuity and $10 \mathrm{~m}$ of Horizontal Accuracy.

The study has selected the waters surrounding the Canary Islands, within the south west border of coverage of EGNOS, to perform a kinematic test campaign from $7^{\text {th }}$ November 2018 to $21^{\text {st }}$ April 2019. For this purpose, we installed a geodetic multi-frequency multi-constellation receiver-antenna pair on-board two vessels from the Armed Institute of the Spanish Civil Guard based in Tenerife.
\end{abstract}

The ESA/UPC GNSS laboratory (gLAB) tool suite has processed the remotely-retrieved GNSS measurements, in conjunction with EGNOS corrections and with cleansed GPS broadcast navigation messages. EGNOS Availability and Continuity have been evaluated within the area comprised between longitudes $13^{\circ} \mathrm{W}$ to $19^{\circ} \mathrm{W}$ and latitudes $27^{\circ} \mathrm{N}$ to $30^{\circ} \mathrm{N}$ with spatial resolution of $0.1^{\circ}$ per $0.1^{\circ}$. The vessel accuracy is evaluated as the difference of coordinates obtained with single-frequency EGNOS solution and the reference trajectory computed with dual-frequency Precise Point Positioning and final orbits from the International GNSS Service.

The EGNOS Maritime Service met all IMO requirements in the geographic area of latitudes northern than $28^{\circ} \mathrm{N}$ and longitudes eastern than $16^{\circ} \mathrm{W}$ after reaching a Signal Availability of $99.999 \%$, a Service Availability in $99.90 \%$ of the predefined rectangular region, and $1.06 \mathrm{~m}$ of Horizontal Accuracy at the 95 th percentile. In contrast, the Service Continuity requirement (only required for coastal waters) was met in $62.50 \%$ of the predefined region. We conclude that the continuity risk is the most limiting factor for expanding the EGNOS Maritime Service along the coastal waters of Canary Islands, in the EGNOS south-west border of coverage. 


\section{INTRODUCTION}

The Global Navigation Satellite System (GNSS) has improved the efficiency and accuracy of transportation means. In terms of safety, Augmentation Systems provide vertical and lateral guidance to aircrafts complying with stringent requirements established by the International Civil Aviation Organization [1]. Furthermore, Augmentation Systems can support applications in other transportation sectors such as maritime, railways and road [2].

The potential use of Satellite Based Augmentation System (SBAS) to support new services for maritime applications has been studied in the European [3] and in the North America [4] regions, taking into consideration the requirements of the International Maritime Organization (IMO). In particular, those requirements established in its Resolution A.1046 (27) [5] which are listed in Table 1 for the self-consistency of this paper.

The coverage offered by a SBAS-based navigation service for maritime applications would enhance the present situation, in which maritime users rely on Differential GNSS (DGNSS) corrections and integrity information for GNSS signals broadcast in real-time by approximately 350 reference stations worldwide distributed that belong to the International Association of Maritime Aids to Navigation and Lighthouse Authorities (IALA) [6].

The aim of the present contribution is to assess the compliance of the European Geostationary Navigation Overlay System (EGNOS), operational since 2009, against IMO requirements. In particular, we used the most demanding requirements in harbour entrances, harbour approaches and coastal waters. In what follows, we refer to as EGNOS 1046 Maritime Service in accordance to the numbering of the IMO Resolution.

The paper is organized as follows. Next section describes the data and experimental setup used. Then, the methodology and the different GNSS processing steps are described in detail. After that, the results of every assessed metric are detailed, including some insights of the GNSS data processing. The paper concludes identifying the geographic area in which the EGNOS 1046 Maritime Service met IMO requirements, identifying the most limiting factor.

Table 1 Requirements of the International Maritime Organization established in its Resolution A.1046 (27) [5]

\begin{tabular}{|l|c|c|}
\hline \multirow{2}{*}{\multicolumn{1}{|c|}{ Parameter }} & \multicolumn{2}{c|}{ Navigation Phase } \\
\cline { 2 - 3 } & Ocean Waters & $\begin{array}{c}\text { Harbour entrances, harbour approaches and } \\
\text { coastal waters }\end{array}$ \\
\hline Horizontal Accuracy 95\% & $100 \mathrm{~m}$ & $99.8 \%$ \\
\hline Signal Availability & $99.8 \%$ & $99.97 \%$ \\
\hline Service Continuity (over 15 min) & $\mathrm{n} / \mathrm{a}$ & $2 \mathrm{~s}$ \\
\hline Position update rate & $2 \mathrm{~s}$ & $10 \mathrm{~s}$ \\
\hline Time to Alarm & a & $\begin{array}{c}\text { Maritime Safety Information as soon as } \\
\text { practicable }\end{array}$ \\
\hline System coverage & Adequate & Adequate \\
\hline
\end{tabular}

a. Generation of integrity warnings in cases of system malfunctions, non-availability or discontinuities

b. Taking into account the radio frequency environment, the coverage of the system should be adequate to provide position fixing throughout this phase of navigation. 


\section{DATA}

The study has selected the waters surrounding the Canary Islands to perform the kinematic test with two vessels from the Armed Institute of the Spanish Civil Guard based in Tenerife and depicted in Figure 1. The campaign started on 7th November 2018 (DoY 311 of 2018) and finished on $21^{\text {st }}$ April 2019 (DoY 111 of 2019). Due to technical and operational reasons, MT-50 was used until $15^{\text {th }}$ February 2019 (DoY 46 of 2019) and EC2259 from $18^{\text {th }}$ of February 2019 (DoY 49 of 2019) until the end of the data campaign.

Figure 2 depicts the experimental setup necessary to perform the experimental kinematic campaign, which are listed in Table 2 . A geodetic multi-frequency multi-constellation GNSS Septentrio PolarX5 receiver and a PolaNt-x MF antenna have been installed onboard the two aforementioned vessels, together with the necessary equipment to retrieve its data remotely using a $4 \mathrm{G}$ modem.

The other data files involved in the assessment are GPS broadcast navigation files and EGNOS messages. Those have been gathered from public web servers. In particular, the RINEX navigation files are download from the International GNSS Service (IGS) [7], whereas EGNOS differential corrections have been download from the SERENAD Data Server that belongs to National Centre for Space Studies (CNES).
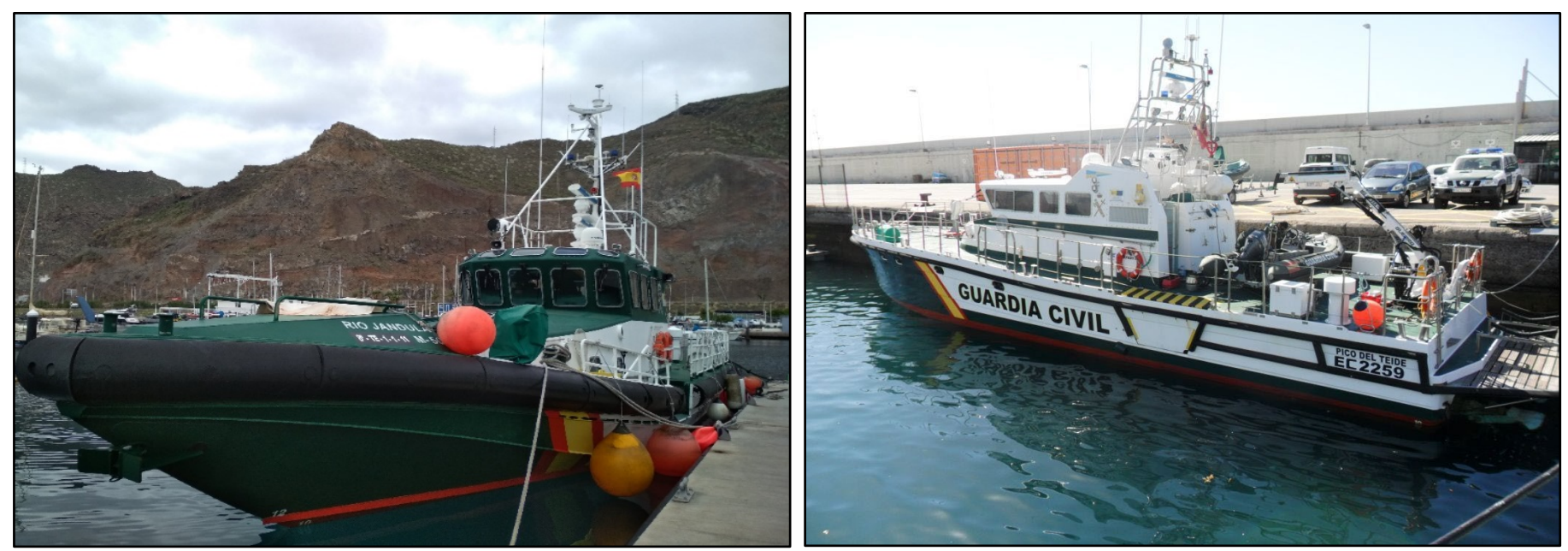

Figure 1: Guardia Civil’s vessels used: M-50 “Río Jándula” (left) and EC2259 "Pico del Teide” (right).

Table 2. List of Components installed in the vessels from the Spanish police Guardia Civil

\begin{tabular}{|l|c|l|}
\hline \multicolumn{1}{|c|}{ Name } & Model & \multicolumn{1}{c|}{ Description } \\
\hline Antenna Septentrio Polan-x MF & 13725 & Antenna which obtains the RF signal from GNSS satellites. \\
\hline Septentrio Receiver PolaRx5e & 4801021 & Receiver that is responsible to collect the data from the antenna. \\
\hline $\begin{array}{l}\text { RF Cable of 30m TNC-m to } \\
\text { TNC-m }\end{array}$ & 215702 & $\begin{array}{l}\text { Cable which connects the receiver to the antenna. 30 m RF cable } \\
\text { TNC-m to TNC-m (RG223). Max. attenuation 17 dB @ 1500 MHz, } \\
\text { static bending radius 26 mm, cable diameter 5.3 mm. }\end{array}$ \\
\hline Rasberry pi 3 b+ & 2ABCB-RPI3BP & $\begin{array}{l}\text { Management unit responsible to download the GNSS data stored in } \\
\text { the receiver and upload it to Dropbox. }\end{array}$ \\
\hline Router 4G Alcatel MW40V & MW40V-2AALIB1 & Router which allows the management unit to connect to Internet. \\
\hline Surge Guard & N/A & Multi-socket adaptor where connect the devices of the equipment. \\
\hline Fan ELUTENG USB & N/A & $\begin{array}{l}\text { Small size fan responsible to extract the hot air avoiding thermal } \\
\text { variations on the GNSS receiver. }\end{array}$ \\
\hline External Battery Zendure A2 & ZDA2P33-b & $\begin{array}{l}\text { External battery to power the management unit when there is no } \\
\text { current from the dock or engines, avoiding data gaps in such } \\
\text { transition. }\end{array}$ \\
\hline $\begin{array}{l}\text { Adapter Battery Charger } \\
\text { AUKRU Micro USB 5V 3A }\end{array}$ & N/A & Socket which keeps the battery connected to the vessel current. \\
\hline Waterproof Suitcase TecTake & 402412 & $\begin{array}{l}\text { Watertight case modified to contain and protect the equipment, to } \\
\text { install it a ventilation and some holes to allow cables. }\end{array}$ \\
\hline Flange & N/A & The flange is used to fix the antenna at the top of the vessel pole. \\
\hline
\end{tabular}




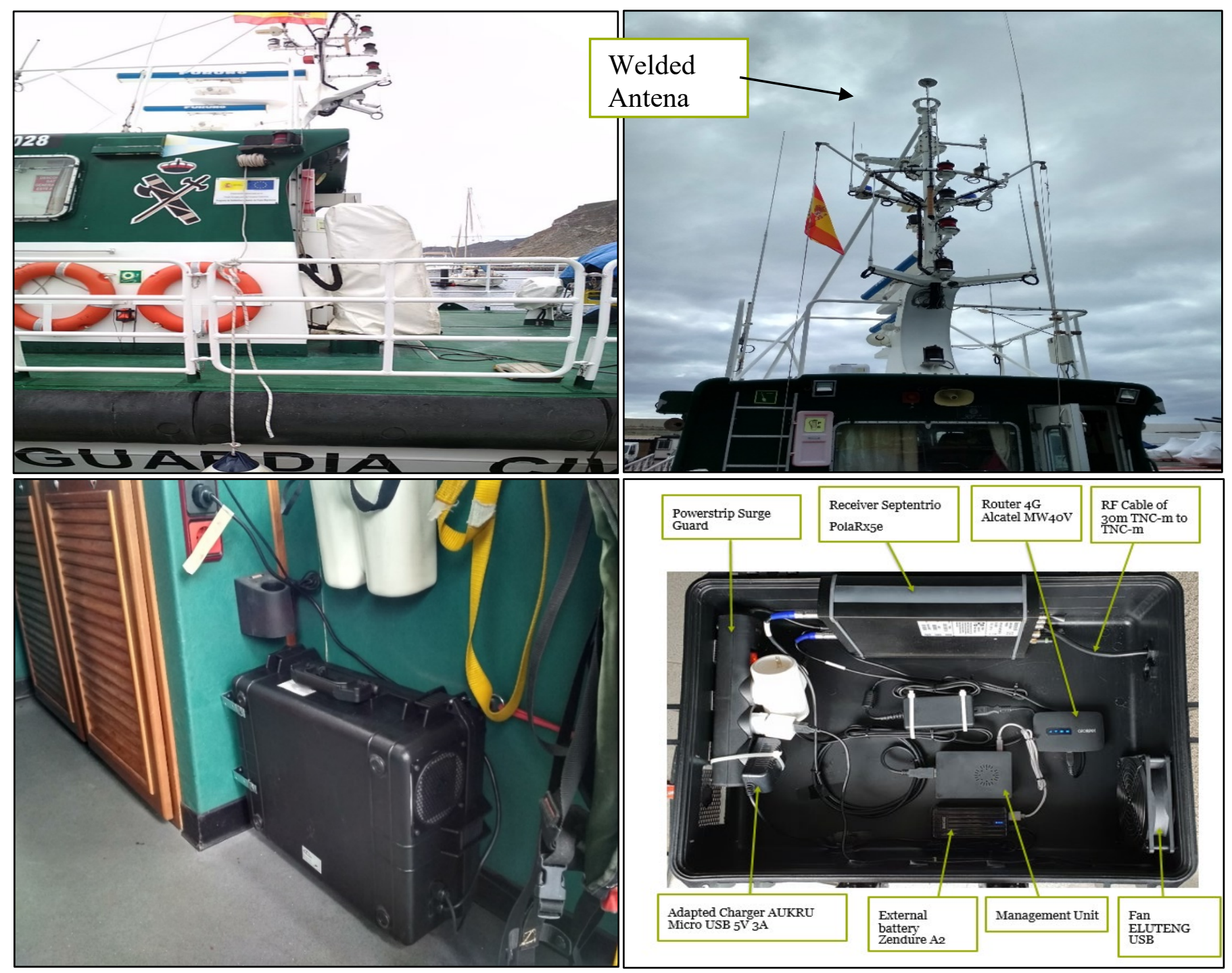

Figure 2: Experimental set up used in the kinematic data collection that has been installed on the vessels from Guardia Civil (top left): A GNSS antenna in the pole (top right), and waterproof suitcase (bottom left) containing the GNSS receiver, a $4 \mathrm{G}$ router and other necessary equipment (bottom right).

\section{METHODOLOGY}

Once the data collection was completed, the first step of the GNSS data processing was to cleanse the navigation RINEX files following the methodology presented in [8], removing potential errors and inconsistencies from different sources. The removed errors include, for instance, data-logging errors and/or hardware/software bugs, losses of navigation messages, different transmission time, among others. In contrast, the EGNOS files are already consolidated by CNES and did not require further processing.

The second step consists in the evaluation of the Availability and Continuity of the EGNOS Maritime Service following a fault-free receiver approach. That is, a receiver that is assumed to be in continuous signal tracking, without cycle-slips, all GPS navigation data and EGNOS corrections available, and no environmental effects. We investigated the performance of the EGNOS Maritime Service where the rover receiver has navigated. That is, the area comprised between longitudes $13^{\circ} \mathrm{W}$ to $19^{\circ} \mathrm{W}$ and latitudes $27^{\circ} \mathrm{N}$ to $30^{\circ} \mathrm{N}$, in the south west border of coverage of the current EGNOS service area. 
The third step is the accuracy and integrity assessment of the vessel trajectory. For this purpose, we have computed a reference trajectory using the Precise Point Positioning (PPP) technique [9] and final orbits from IGS. The error of the vessel is evaluated as the difference in the coordinates obtained with single-frequency EGNOS maritime solution and those obtained with the dualfrequency ionospheric-free PPP solution.

We have used the ESA/UPC GNSS laboratory (gLAB) tool suite [10] as the main software to perform the calculations. The SBAS maritime template in gLAB has been used, changing the satellite elevation mask from 5 to 7.5 degrees. Notice that in Table 1 no requirements on the Alarm Limits (ALs) based on SBAS Protection Levels (PLs) are indicated. Therefore, the Horizontal and Vertical Alarm Limits (HAL and VAL) have been disabled in gLAB by taking a huge value of $100 \mathrm{~km}$. In contrast, and according to IALA [11] we set the Dilution of Precision (DOP) mask to exclude epochs with geometries PDOP $\geq 6$ and HDOP $\geq 4$, to ensure that the position information can be reliably used for navigation purposes. The Service Continuity is computed using a fixed window of 15 minutes as Continuity Time Interval (CTI) according to the IALA guidelines [12].

\section{RESULTS}

The EGNOS Maritime Service met the IMO requirement of Signal in Space (SiS) Availability of $99.8 \%$. According to Table 3, the individual satellites in Geosynchronous Equatorial Orbit (GEO) broadcasting EGNOS messages already achieved such requirement. A simultaneous data gap of $8 \mathrm{~s}$ was observed in the SiS of the satellites PRN123 and PRN136, which gives rise to a combined signal availability of $99.999 \%$ of the time.

In terms of Availability and Continuity, Figure 3 depicts the performance of the EGNOS Maritime Service in its south west border of coverage using a resolution of $1^{\circ}$ per $1^{\circ}$. The results are depicted without applying any kind of interpolation strategy to avoid any artefact or smoothing. The maps evidence that the assessment in the region comprising the Canary Islands is challenging because the current EGNOS exhibits a spatial gradient in performance.

Table 3. EGNOS SIS outages occurred from 07/11/2018 to 21/04/2019

\begin{tabular}{|c|c|c|c|}
\hline Geostationary PRN & Days & Data Gaps (s) & Availability (\%) \\
\hline 123 & 165 & 2862 & 99.98 \\
\hline 136 & 165 & 1359 & 99.99 \\
\hline 123 and 136 & 165 & 8 & 99.999 \\
\hline
\end{tabular}
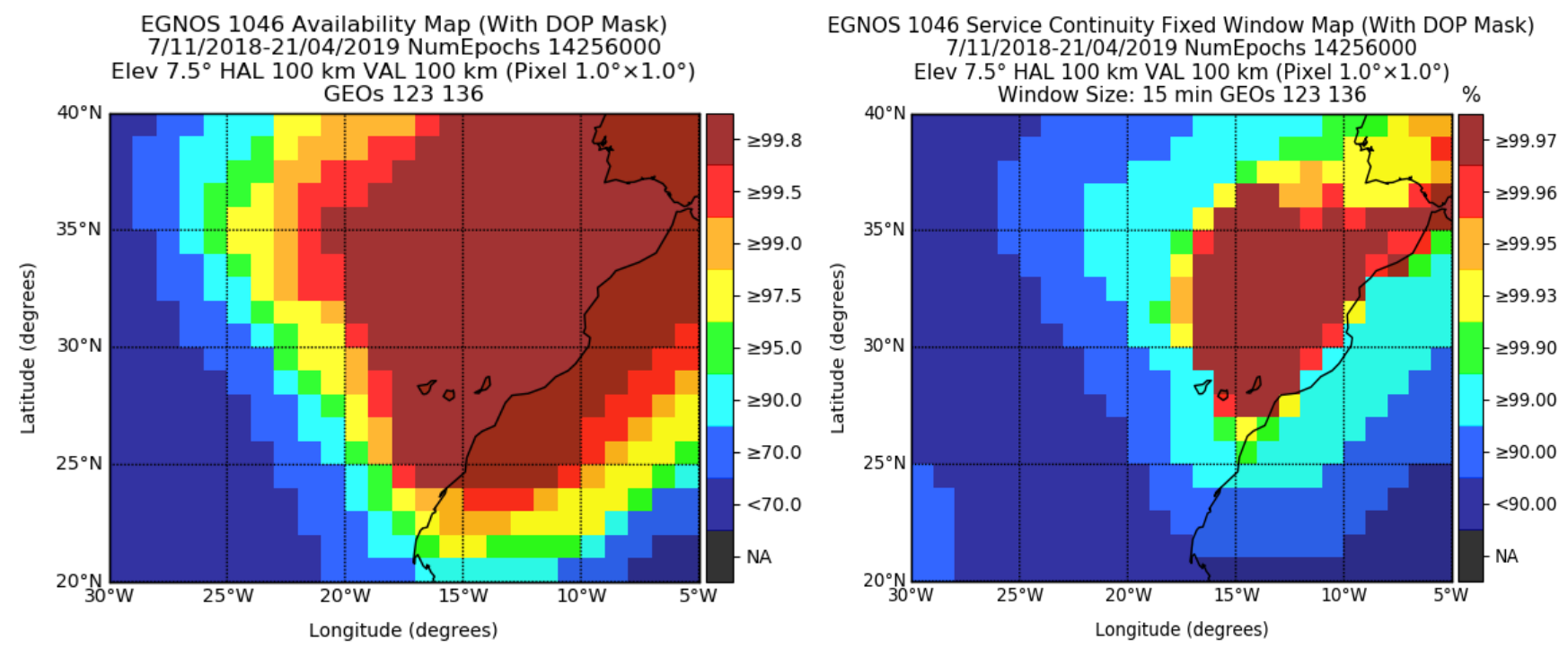

Figure 3. EGNOS performance at its south west border of coverage. Left plot shows the service availability with the DOP mask activated and right plots shows the service continuity using a fixed window of 15 minutes. 
The observed gradient in performance over the Canary Islands required the use of a finer resolution. Figure 4 depicts the area comprised between longitudes $13^{\circ} \mathrm{W}$ to $19^{\circ} \mathrm{W}$ and latitudes $27^{\circ} \mathrm{N}$ to $30^{\circ} \mathrm{N}$, where every square pixel represents $0.1^{\circ}$ per $0.1^{\circ}$. The top row depicts the Availability assessment, whereas the bottom row shows the Continuity assessment. The left column shows the values at the individual cells and the right column, its compliance against the most demanding requirements of IMO in terms of harbour entrances, harbour approaches and coastal waters. In order to give a quantitative result, we draw a rectangular region surrounding the Canary Islands, in which we evaluate the results numerically.

Figure 4 indicates that the EGNOS Maritime Service met the IMO requirement of $99.8 \%$ of Availability in $99.90 \%$ of the predefined rectangular region. In contrast, the bottom row depicts how the EGNOS Maritime Service only met the Continuity requirement of $99.97 \%$ in a smaller area of $62.50 \%$ of the predefined region. Obviously, the use of a more refined area (e.g., waters within 12 nautical miles of the coast) would lead to different percentage results. Irrespectively of the area chosen, Figure 4 shows that the most stringent IMO requirements in terms of continuity in coastal waters (note that ocean waters do not have a continuity requirement) are met in latitudes north of $28.5^{\circ} \mathrm{N}$ and longitudes east of $16.5^{\circ} \mathrm{W}$.

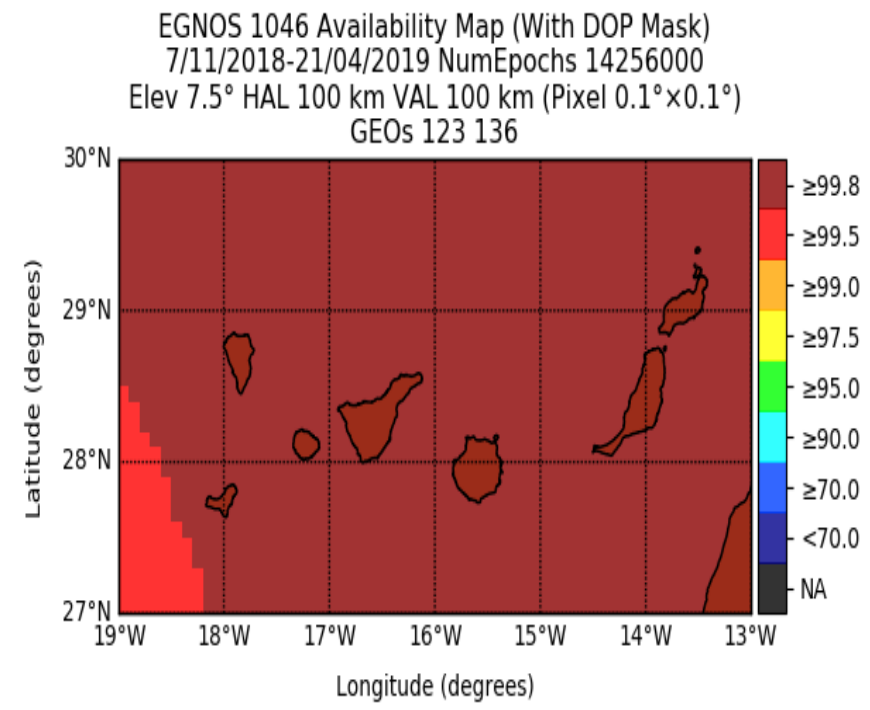

EGNOS 1046 Service Continuity Fixed Window Map (With DOP Mask) 7/11/2018-21/04/2019 NumEpochs 14256000

Elev 7.5 HAL $100 \mathrm{~km}$ VAL $100 \mathrm{~km}$ (Pixel $\left.0.1^{\circ} \times 0.1\right)$

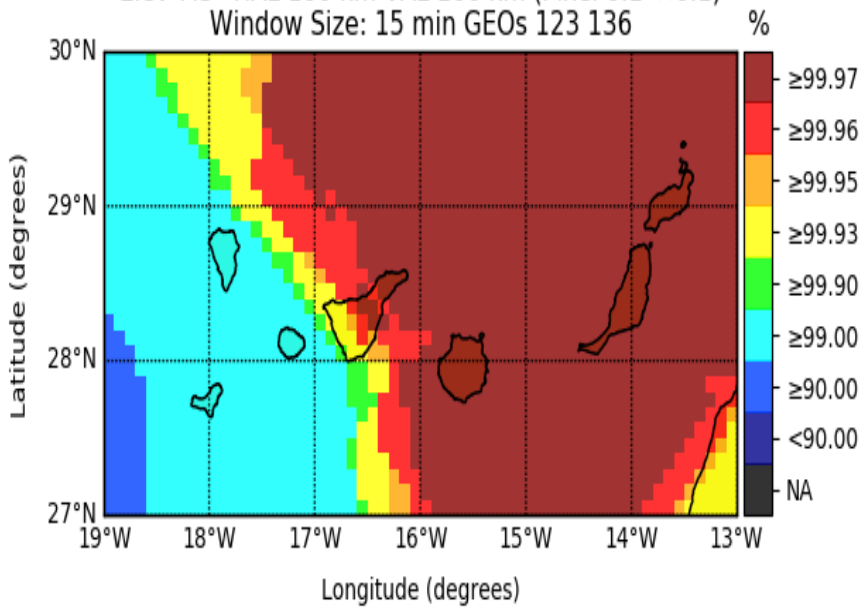

EGNOS 1046 Availability Map (With DOP Mask) 7/11/2018-21/04/2019 NumEpochs 14256000 Elev $7.5^{\circ} \mathrm{HAL} 100 \mathrm{~km}$ VAL $100 \mathrm{~km}$ (Pixel $0.1^{\circ} \times 0.1^{\circ}$ )

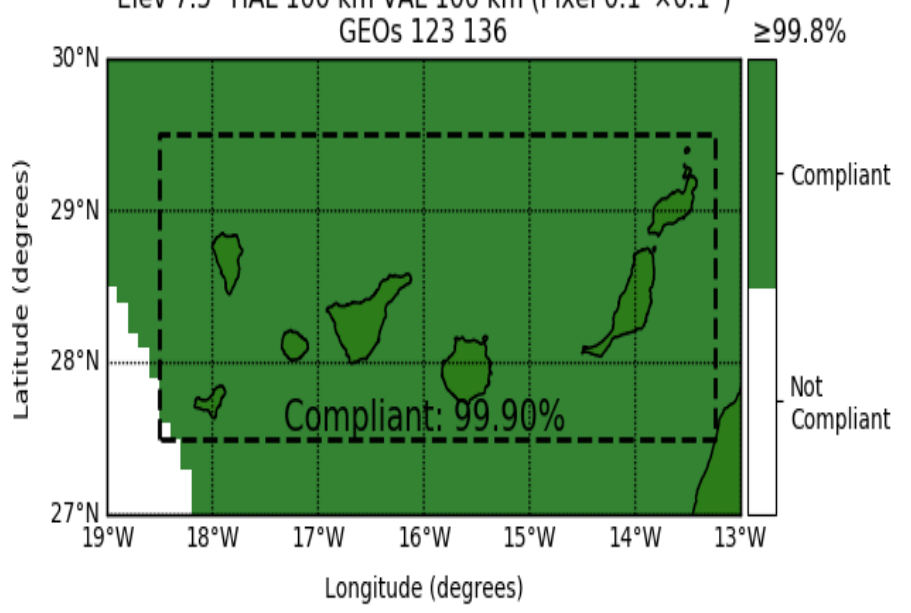

EGNOS 1046 Service Continuity Fixed Window Map (With DOP Mask) 7/11/2018-21/04/2019 NumEpochs 14256000 Elev 7.5 HAL $100 \mathrm{~km}$ VAL $100 \mathrm{~km}$ (Pixel $0.1^{\circ} \times 0.1$ )

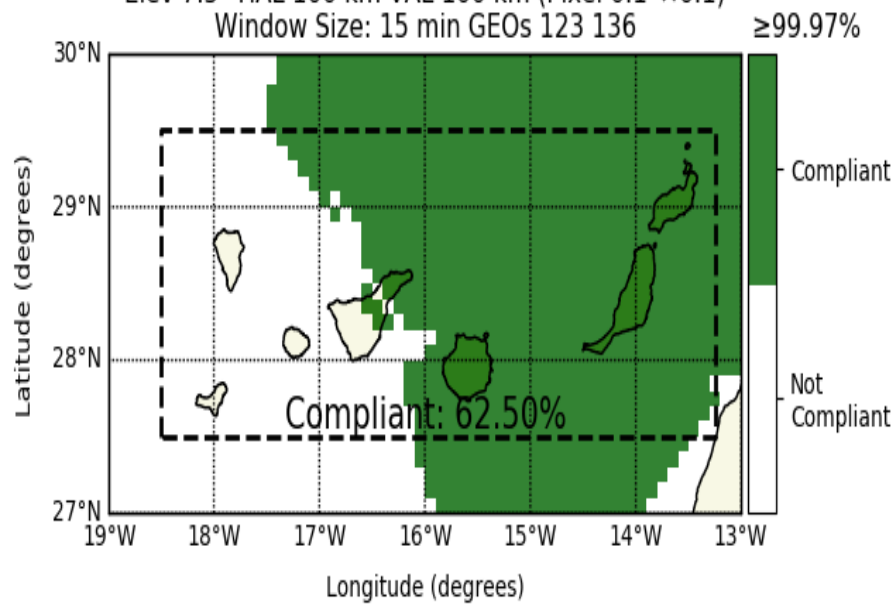

Figure 4. Zoom of Figure 3 at Canary Islands with a finer grid of $0.1^{\circ}$ per $0.1^{\circ}$. Left column shows the service availability (top row) and continuity (bottom row) and right column shows its compliance with IMO requirement of $99.8 \%$ and $99.97 \%$ respectively. 
The intersection of the previously depicted maps of Service Availability and Service Continuity yields the Service Coverage map, shown in Figure 5. That is, Service Coverage is defined as the region in which it is simultaneously achieved a Service Availability of $99.8 \%$ and Service Continuity of $99.97 \%$. This occurs by latitudes northern than +28 degrees and longitudes eastern than -16 degrees. By comparing the Service Coverage results with Figure 4, it can be seen that the region in which the Service Coverage meets simultaneously the two IMO requirements coincides with the Service Continuity. That is, the Service Availability does not impose a limitation on the coverage.

The analysis of the root cause of the lack of continuity in the EGNOS Maritime Service falls out of the scope of the present contribution. However, the authors performed a further analysis dedicated to identify whether the cause could be attributable to values of Horizontal and Positioning Dilution of Precision larger than the specified thresholds (PDOP $\geq 6$ and HDOP $\geq 4$ ) or to the unavailability of Ionospheric Corrections present in the EGNOS messages. Figure 6 and Figure 7 reveal the mean HDOP and PDOP values were respectively under 4 and 6 and that the availability of ionosphere corrections was over $99.8 \%$ of the time. This result suggests that the cause resides somewhere else.

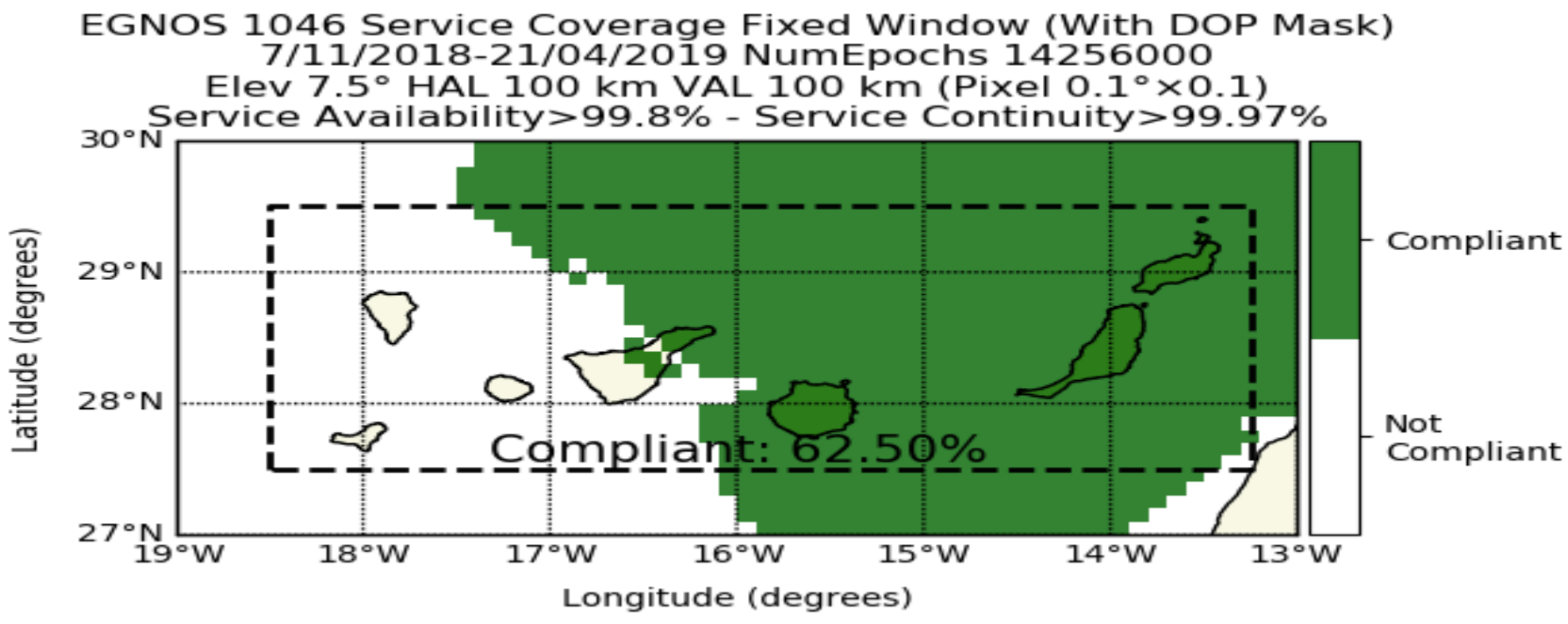

Figure 5. EGNOS Maritime Service Coverage map, defined as the simultaneous intersection maps of Availability over $\mathbf{9 9 . 8} \%$ and Continuity over $\mathbf{9 9 . 7 \%}$.
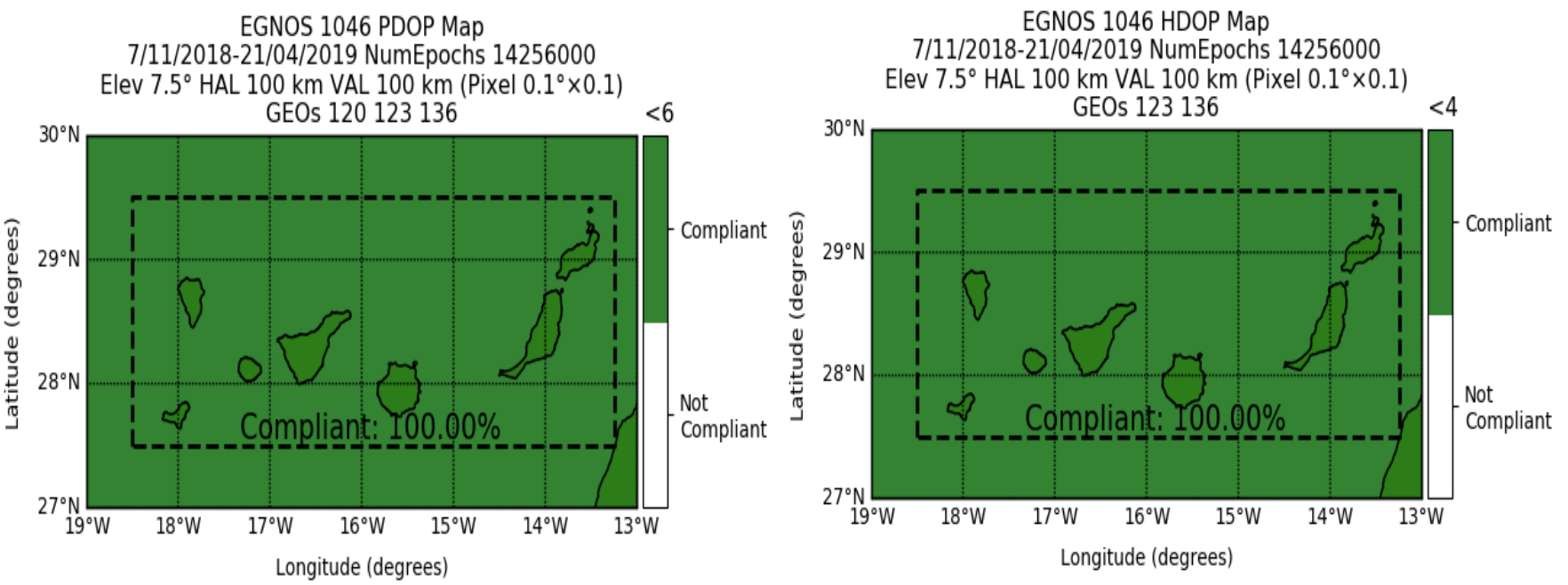

Figure 6. Dilution of Precision maps: Positioning DOP (left) and Horizontal DOP (right). 
The last part of the present study finishes with the assessment of the accuracy and integrity of the EGNOS Maritime Service. For that purpose, the two aforementioned vessels MT-50 and EC2259 have been navigating around the Canary Islands of Tenerife, La Palma and La Gomera, see Figure 9. During the kinematic data collection campaign, the most demanding phase of the navigation requirements of Table 1 has been assessed. Indeed, the bottom panels of Figure 9 depict several harbour entrances, harbour approaches and navigation in coastal waters.

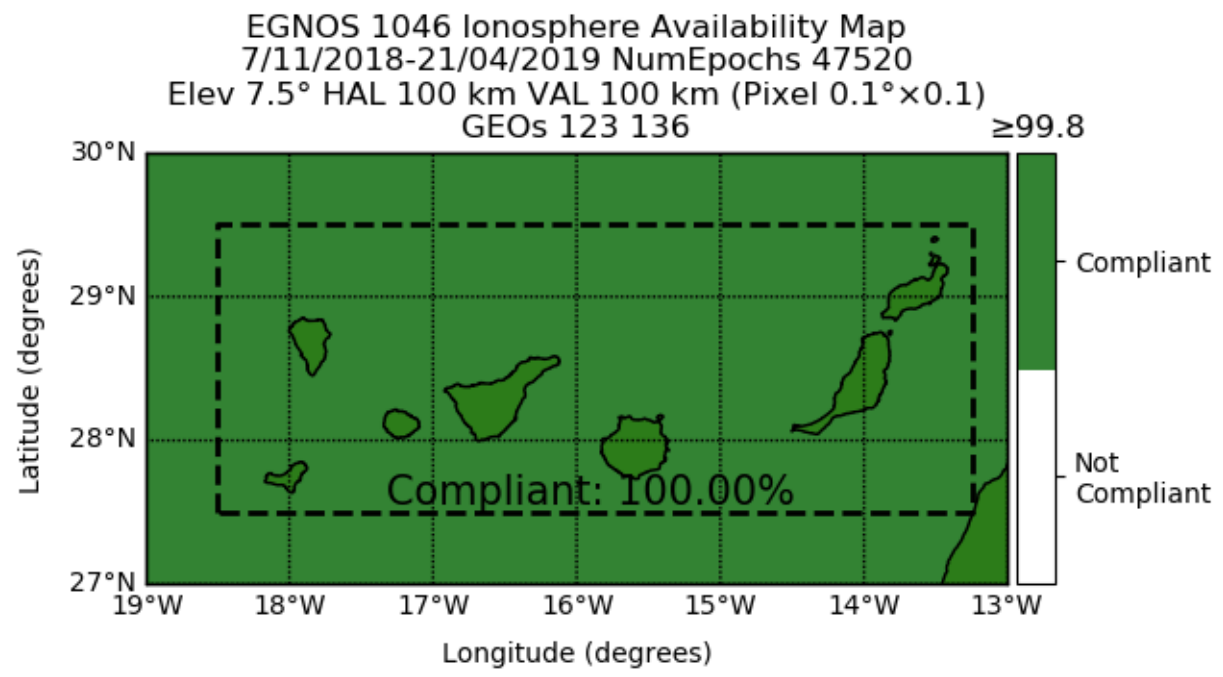

Figure 7. Availability of Ionosphere Corrections in the Canary Islands during the kinematic campaign.

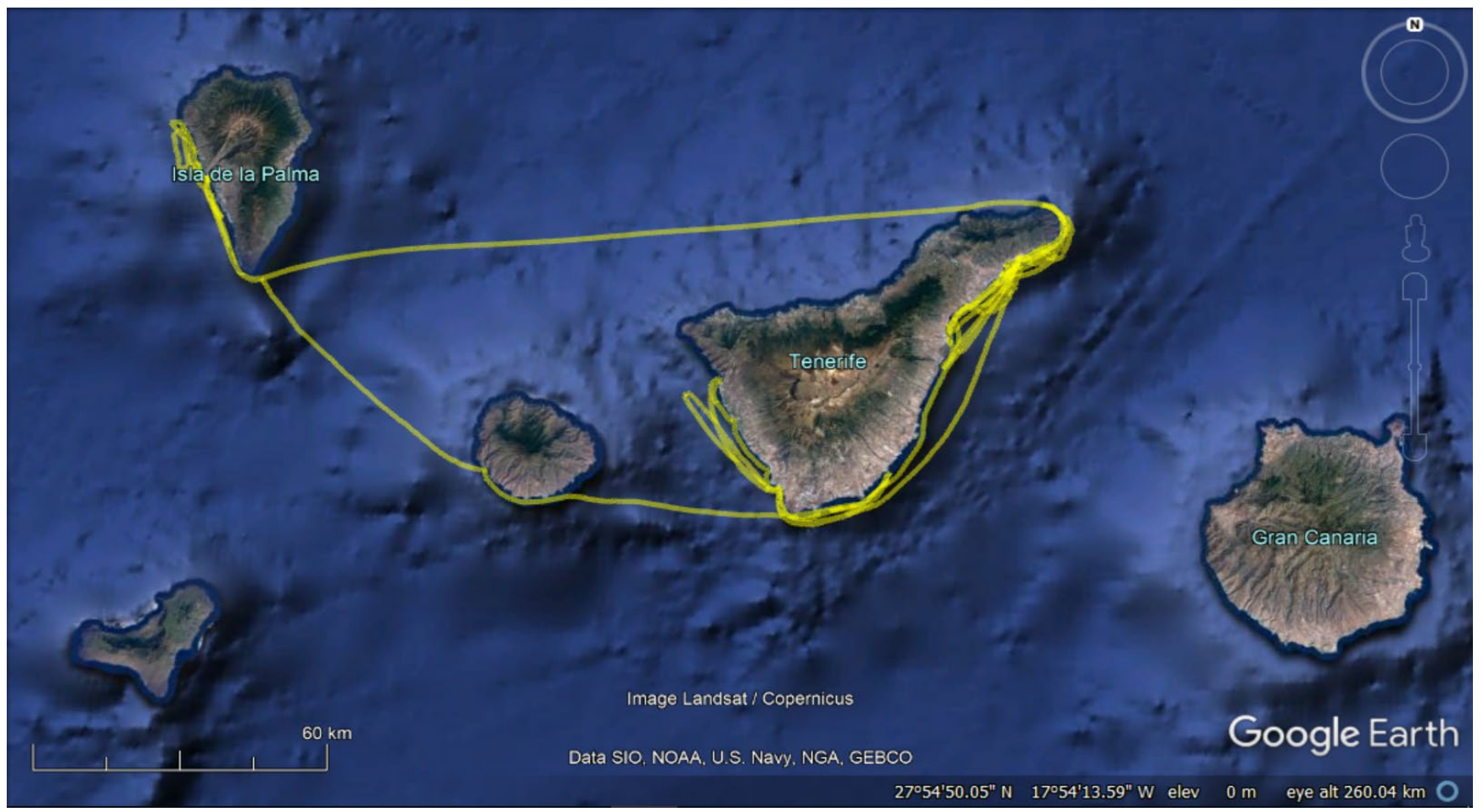

Figure 8. Aggregated trajectories for the MT-50 and EC2259 vessels from 7/11/2018 to 21/04/2019. 
Table 4 summarizes the results of the kinematic evaluation using the $95^{\text {th }}$ percentiles, whereas Table 5 in the appendix details each navigation day. The kinematic campaign totals over 12 million epochs, which is more than 148 days. However, the protection levels have been computed using the integrity information contained in the SBAS messages, whereas the navigation errors are evaluated with respect to the reference trajectory computed with PPP. It can be seen that the horizontal and vertical errors of the EC2259 vessel are worse than those of the MT50. The reason explaining this deterioration is that the upper part of the pole where the GNSS antenna was installed in the second vessel had more antennae and other equipment in than the first vessel. In contrast, the horizontal and vertical protection levels are more similar, indicating that the geometry of the satellites is comparable.
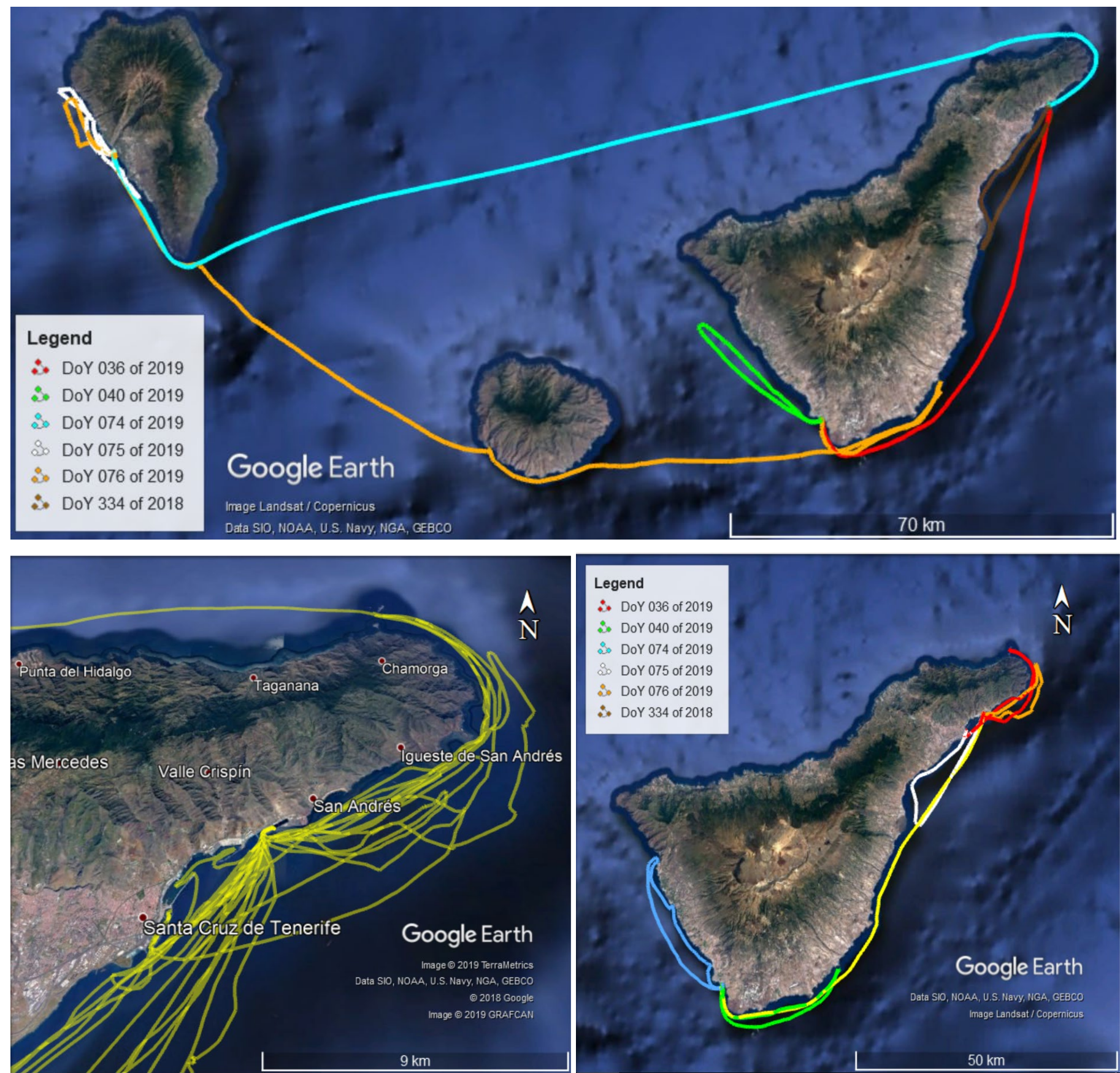

Figure 9. Zoom of Figure 8 for some selected days. 
The navigation errors in the horizontal component of the two vessels is $1.15 \mathrm{~m}$, after aggregating more than twelve million epochs. Therefore, the EGNOS Maritime Service met the IMO requirement of $10 \mathrm{~m}$ of horizontal accuracy at the 95th percentile. It might be surprising the large values observed in the Protection Levels of both components. The reason is that in the maritime processing a conservative bound of $8 \mathrm{~m}$ is used to bound the degradation of the fast and long term corrections with respect to time. The values of the PL could be lowered by taking account the values present in SBAS Message Type 10, as it is currently done in the Aviation domain [13] processing.

Table 4. Aggregated results of the accuracy and integrity of the vessels in terms of Horizontal and Vertical Positioning Error (HPE and VPE) and Horizontal and Vertical Protection Levels (HPL and VPL). The values are expressed in meters and in form of 95th percentiles.

\begin{tabular}{|c|c|c|c|c|c|}
\hline VESSEL & EPOCHS (s) & 95th HPE (m) & 95th HPL (m) & 95th VPE (m) & 95th VPL (m) \\
\hline MT-50 & 8473010 & 1.06 & 68.35 & 1.34 & 139.90 \\
\hline EC2259 & 4355145 & 1.29 & 67.29 & 1.49 & 140.42 \\
\hline ALL & 12828155 & 1.15 & 67.89 & 1.39 & 140.03 \\
\hline
\end{tabular}

\section{CONCLUSIONS}

Our study concludes with the observation that EGNOS Maritime Service met all IMO requirements in the geographic area of latitudes north of $28^{\circ} \mathrm{N}$ and longitudes east of $15.5^{\circ} \mathrm{W}$. The continuity risk is, by far, the most limiting factor for expanding the EGNOS Maritime Service along the coastal waters of Canary Islands, in the EGNOS south-west border of coverage.

\section{ACKNOWLEDGMENTS}

The authors would like to thank the Armed Institute of the Spanish Civil Guard for their assistance with the installation of equipment on-board their vessels that allowed collection of GNSS data, as well as for the navigation days across the Canary waters. The authors acknowledge the use of products provided by the International GNSS Service. EGNOS messages have been downloaded from SERENAD Data Server that belong to National Centre for Space Studies (CNES). The research reported in this paper was financially supported by the European GNSS Agency under contract GSA/OP/12/16/Lot1/SC1.

\section{REFERENCES}

[1] International Civil Aviation Organization, "ANNEX 10 to the Convention on International Civil Aviation, Aeronautical Telecommunications, Vol. I”, November 2009.

[2] Pullen S, Walter T, Enge P, "SBAS and GBAS Integrity for Non-Aviation Users: Moving Away from Specific Risk" Proceedings of the 2011 International Technical Meeting of The Institute of Navigation, San Diego, CA, January 2011, pp. 533-545.

[3] Pintor P, Lopez-Martinez M, Roldan R, "SBAS Service Based in IMO Res. A.1046 (27): EGNOS Maritime Performance," Proceedings of the 30th International Technical Meeting of the Satellite Division of The Institute of Navigation (ION GNSS+ 2017), Portland, Oregon, September 2017, pp. 1354-1372. https://doi.org/10.33012/2017.15111

[4] Johnson G, Grayson C, Dhungana G, Delisle J, "An Evaluation of WAAS to Meet Maritime Navigation Requirements in Canadian Waters," Proceedings of the 2019 International Technical Meeting of The Institute of Navigation, Reston, Virginia, January 2019, pp. 146-161. https://doi.org/10.33012/2019.16671 
[5] IMO Resolution A.1046(27), WORLDWIDE RADIONAVIGATION SYSTEM, Adopted on 30 November 2011.

[6] International Association of Marine Aids to Navigation and Lighthouse Authorities. "IALA INFORMATION TABLE OF DGNSS STATIONS Edition 1.0", 21 th March 2019

[7] Beutler G, Rothacher M, Schaer S, Springer T, Kouba J, Neilan R "The International GPS Service (IGS): An interdisciplinary service in support of Earth sciences". Advances in Space Research 23(4):631-653, 13 July 1999

[8] Heng L, "Safe Satellite Navigation with Multiple Constellations: Global Monitoring of GPS and GLONASS Signal-In-Space Anomalies", Ph.D. Dissertation, Stanford University, December 2012.

[9] Zumberge JF, Heflin MB, Jefferson DC, Watkins M, Webb FH, "Precise point positioning for the efficient and robust analysis of GPS data from large networks" Journal Geophysical Research (102):5005-5017, 10 March 1997

[10] Ibáñez D, Rovira-Garcia A, Sanz J, Juan JM, Gonzalez-Casado G, Jimenez-Baños D, López-Echazarreta C, Lapin I, “The GNSS Laboratory Tool Suite (gLAB) updates: SBAS, DGNSS and Global Monitoring System". 9th ESA Workshop on Satellite Navigation Technologies (NAVITEC2018), Noordwijk, The Netherlands. 5-7 December 2018.

[11] International Civil Aviation Organization, “ANNEX 17 to the Resolution MSC.401(95), 8 June 2015. Performance Standards for Multi-System Shipborne Radio Navigation Receivers.

[12] IALA Guideline No. 1112 On Performance and Monitoring of DGNSS Services in the Frequency Band 283.5-325KHz. Edition 1. May 2015

[13] RTCA DO-229D. Minimum Operational Performance Standards for Global Positioning System/Wide Area Augmentation System Airborne Equipment, 13 December 2006

\section{APPENDIX}

Table 5. Detailed results of the kinematic assessment. For each navigation day (ID), it can be read the name of the vessel, the number of epochs in seconds, the travelled distance (in metres) and the 95th percentile value of the horizontal and vertical positioning error and the corresponding protection levels (in metres).

\begin{tabular}{|c|c|c|c|c|r|r|r|r|r|}
\hline ID & Vessel & Year & DoY & Epochs (s) & Distance (m) & HPE (m) & HPL (m) & VPE (m) & VPL (m) \\
\hline 1 & MT-50 & 2018 & 311 & 86400 & 3036 & 1.48 & 66.15 & 1.55 & 139.68 \\
\hline 2 & MT-50 & 2018 & 312 & 86400 & 3542 & 1.10 & 65.35 & 1.44 & 147.57 \\
\hline 3 & MT-50 & 2018 & 313 & 86400 & 4101 & 0.94 & 66.27 & 1.25 & 137.99 \\
\hline 4 & MT-50 & 2018 & 314 & 86400 & 4717 & 0.75 & 65.77 & 1.07 & 135.91 \\
\hline 5 & MT-50 & 2018 & 315 & 86400 & 3634 & 1.40 & 70.00 & 1.58 & 140.93 \\
\hline 6 & MT-50 & 2018 & 316 & 86400 & 3694 & 1.29 & 65.97 & 1.95 & 139.45 \\
\hline 7 & MT-50 & 2018 & 317 & 86400 & 3429 & 1.35 & 69.61 & 1.50 & 139.49 \\
\hline 8 & MT-50 & 2018 & 318 & 86400 & 3182 & 1.11 & 67.64 & 1.45 & 135.90 \\
\hline 9 & MT-50 & 2018 & 319 & 86400 & 10585 & 1.55 & 67.38 & 1.47 & 139.17 \\
\hline 10 & MT-50 & 2018 & 320 & 86400 & 3441 & 0.89 & 65.87 & 1.34 & 136.68 \\
\hline 11 & MT-50 & 2018 & 321 & 86384 & 4588 & 0.90 & 67.42 & 1.45 & 139.08 \\
\hline 12 & MT-50 & 2018 & 322 & 86400 & 6323 & 0.82 & 71.74 & 1.59 & 142.71 \\
\hline 13 & MT-50 & 2018 & 323 & 86400 & 5196 & 1.22 & 68.12 & 1.53 & 138.60 \\
\hline 14 & MT-50 & 2018 & 324 & 86400 & 3388 & 0.84 & 67.49 & 1.24 & 137.94 \\
\hline 15 & MT-50 & 2018 & 325 & 86400 & 4067 & 1.05 & 68.95 & 1.53 & 139.40 \\
\hline 16 & MT-50 & 2018 & 326 & 86400 & 2925 & 0.85 & 68.24 & 1.28 & 138.46 \\
\hline 17 & MT-50 & 2018 & 327 & 86400 & 2970 & 1.11 & 73.70 & 1.41 & 156.85 \\
\hline 18 & MT-50 & 2018 & 328 & 86400 & 2598 & 0.94 & 71.75 & 1.40 & 154.22 \\
\hline 19 & MT-50 & 2018 & 329 & 86400 & 2147 & 0.89 & 66.52 & 1.34 & 139.38 \\
\hline 20 & MT-50 & 2018 & 330 & 86400 & 1926 & 1.23 & 69.02 & 1.53 & 138.77 \\
\hline 21 & MT-50 & 2018 & 331 & 86400 & 2621 & 1.12 & 68.34 & 1.45 & 135.26 \\
\hline
\end{tabular}




\begin{tabular}{|c|c|c|c|c|c|c|c|c|c|}
\hline ID & Vessel & Year & DoY & Epochs (s) & Distance (m) & HPE (m) & HPL (m) & VPE (m) & VPL (m) \\
\hline 22 & MT-50 & 2018 & 332 & 86400 & 3265 & 1.10 & 67.66 & 1.37 & 138.52 \\
\hline 23 & MT-50 & 2018 & 333 & 86400 & 2961 & 1.38 & 70.51 & 1.21 & 140.47 \\
\hline 24 & MT-50 & 2018 & 334 & 86400 & 65755 & 0.94 & 68.46 & 1.35 & 136.12 \\
\hline 25 & MT-50 & 2018 & 335 & 86400 & 2565 & 1.03 & 71.62 & 1.46 & 141.81 \\
\hline 26 & MT-50 & 2018 & 336 & 86400 & 2650 & 0.85 & 70.48 & 1.30 & 139.42 \\
\hline 27 & MT-50 & 2018 & 337 & 86400 & 3514 & 0.83 & 72.25 & 1.34 & 135.40 \\
\hline 28 & MT-50 & 2018 & 338 & 86400 & 3419 & 0.86 & 74.90 & 1.04 & 146.61 \\
\hline 29 & MT-50 & 2018 & 339 & 86400 & 3327 & 0.69 & 69.56 & 1.14 & 138.80 \\
\hline 30 & MT-50 & 2018 & 340 & 86400 & 3330 & 1.00 & 72.74 & 1.42 & 140.45 \\
\hline 31 & MT-50 & 2018 & 341 & 86400 & 2792 & 1.03 & 75.13 & 1.38 & 144.78 \\
\hline 32 & MT-50 & 2018 & 342 & 86400 & 2699 & 1.19 & 72.51 & 1.80 & 147.72 \\
\hline 33 & MT-50 & 2018 & 343 & 86400 & 2401 & 1.25 & 72.28 & 1.78 & 138.32 \\
\hline 34 & MT-50 & 2018 & 344 & 86400 & 3060 & 1.01 & 71.02 & 1.19 & 154.20 \\
\hline 35 & MT-50 & 2018 & 345 & 86400 & 3052 & 1.00 & 67.15 & 1.15 & 137.28 \\
\hline 36 & MT-50 & 2018 & 346 & 86400 & 3036 & 1.08 & 69.65 & 1.44 & 138.76 \\
\hline 37 & MT-50 & 2018 & 347 & 71199 & 2987 & 1.15 & 68.16 & 1.26 & 144.11 \\
\hline 38 & MT-50 & 2018 & 349 & 86400 & 4302 & 1.29 & 70.38 & 1.40 & 137.50 \\
\hline 39 & MT-50 & 2018 & 350 & 86400 & 3624 & 0.95 & 68.83 & 1.35 & 141.49 \\
\hline 40 & MT-50 & 2018 & 351 & 86400 & 3402 & 0.83 & 68.44 & 1.49 & 145.19 \\
\hline 41 & MT-50 & 2018 & 352 & 86400 & 2979 & 0.75 & 71.44 & 1.50 & 171.82 \\
\hline 42 & MT-50 & 2018 & 353 & 86400 & 3064 & 0.86 & 71.87 & 1.24 & 143.24 \\
\hline 43 & MT-50 & 2018 & 354 & 86400 & 2967 & 0.82 & 66.35 & 1.20 & 156.08 \\
\hline 44 & MT-50 & 2018 & 355 & 86400 & 2919 & 0.64 & 71.98 & 1.15 & 145.10 \\
\hline 45 & MT-50 & 2018 & 356 & 86400 & 2535 & 0.75 & 71.77 & 1.52 & 139.15 \\
\hline 46 & MT-50 & 2018 & 357 & 86400 & 5030 & 1.11 & 66.79 & 1.32 & 154.14 \\
\hline 47 & MT-50 & 2018 & 358 & 86400 & 5328 & 0.75 & 68.89 & 1.54 & 139.91 \\
\hline 48 & MT-50 & 2018 & 359 & 76055 & 3698 & 1.06 & 65.01 & 1.35 & 143.46 \\
\hline 49 & MT-50 & 2018 & 360 & 86400 & 2530 & 1.19 & 71.34 & 1.49 & 139.51 \\
\hline 50 & MT-50 & 2018 & 361 & 86400 & 2603 & 1.01 & 72.69 & 1.35 & 137.97 \\
\hline 51 & MT-50 & 2018 & 362 & 86400 & 2923 & 1.15 & 68.91 & 1.38 & 137.11 \\
\hline 52 & MT-50 & 2018 & 363 & 86400 & 2778 & 1.12 & 76.34 & 1.46 & 139.31 \\
\hline 53 & MT-50 & 2018 & 364 & 86400 & 2206 & 1.10 & 75.23 & 1.28 & 143.66 \\
\hline 54 & MT-50 & 2018 & 365 & 86400 & 3282 & 1.14 & 74.71 & 1.15 & 183.78 \\
\hline 55 & MT-50 & 2019 & 1 & 86400 & 3753 & 0.87 & 63.57 & 1.54 & 142.00 \\
\hline 56 & MT-50 & 2019 & 2 & 86400 & 3157 & 0.95 & 64.90 & 1.27 & 143.20 \\
\hline 57 & MT-50 & 2019 & 3 & 86400 & 2699 & 0.92 & 63.47 & 1.31 & 138.09 \\
\hline 58 & MT-50 & 2019 & 4 & 86400 & 2513 & 1.16 & 68.78 & 1.50 & 140.55 \\
\hline 59 & MT-50 & 2019 & 5 & 86400 & 2549 & 1.07 & 63.81 & 1.29 & 142.20 \\
\hline 60 & MT-50 & 2019 & 6 & 86400 & 4074 & 1.33 & 66.19 & 1.34 & 142.82 \\
\hline 61 & MT-50 & 2019 & 7 & 86400 & 3608 & 0.70 & 68.81 & 1.17 & 141.07 \\
\hline 62 & MT-50 & 2019 & 8 & 86400 & 2868 & 0.78 & 64.85 & 1.26 & 142.07 \\
\hline 63 & MT-50 & 2019 & 9 & 86400 & 2421 & 0.82 & 69.09 & 1.14 & 142.43 \\
\hline 64 & MT-50 & 2019 & 11 & 32280 & 1042 & 1.42 & 110.87 & 1.85 & 211.35 \\
\hline 65 & MT-50 & 2019 & 12 & 86400 & 3005 & 1.06 & 69.47 & 1.21 & 143.13 \\
\hline 66 & MT-50 & 2019 & 13 & 86400 & 3531 & 0.82 & 65.01 & 1.25 & 143.12 \\
\hline 67 & MT-50 & 2019 & 14 & 86400 & 3985 & 1.11 & 70.56 & 1.13 & 141.64 \\
\hline 68 & MT-50 & 2019 & 15 & 86400 & 2969 & 0.86 & 65.40 & 1.14 & 140.73 \\
\hline 69 & MT-50 & 2019 & 16 & 86400 & 2498 & 1.22 & 68.64 & 1.47 & 136.08 \\
\hline 70 & MT-50 & 2019 & 17 & 86400 & 3005 & 0.69 & 69.63 & 1.04 & 142.21 \\
\hline 71 & MT-50 & 2019 & 18 & 86400 & 3334 & 0.77 & 64.20 & 1.13 & 140.14 \\
\hline
\end{tabular}




\begin{tabular}{|c|c|c|c|c|c|c|c|c|c|}
\hline ID & Vessel & Year & DoY & Epochs (s) & Distance (m) & HPE (m) & HPL (m) & VPE (m) & VPL (m) \\
\hline 72 & MT-50 & 2019 & 19 & 86400 & 2696 & 0.95 & 67.49 & 1.06 & 135.34 \\
\hline 73 & MT-50 & 2019 & 20 & 86400 & 2302 & 0.99 & 68.97 & 1.02 & 140.67 \\
\hline 74 & MT-50 & 2019 & 21 & 86400 & 2870 & 0.78 & 67.30 & 1.03 & 142.23 \\
\hline 75 & MT-50 & 2019 & 22 & 86078 & 3213 & 1.22 & 63.48 & 1.33 & 134.21 \\
\hline 76 & MT-50 & 2019 & 23 & 86400 & 3190 & 1.00 & 64.62 & 1.25 & 136.38 \\
\hline 77 & MT-50 & 2019 & 24 & 86400 & 3194 & 1.19 & 64.04 & 1.14 & 136.73 \\
\hline 78 & MT-50 & 2019 & 25 & 86400 & 2664 & 1.00 & 70.34 & 1.30 & 151.69 \\
\hline 79 & MT-50 & 2019 & 26 & 86400 & 2082 & 1.06 & 66.73 & 1.12 & 139.20 \\
\hline 80 & MT-50 & 2019 & 27 & 86400 & 2662 & 0.88 & 68.07 & 1.24 & 142.90 \\
\hline 81 & MT-50 & 2019 & 28 & 86400 & 3007 & 0.78 & 64.27 & 1.17 & 138.61 \\
\hline 82 & MT-50 & 2019 & 29 & 86400 & 3027 & 0.78 & 66.77 & 1.28 & 138.17 \\
\hline 83 & MT-50 & 2019 & 30 & 86400 & 3262 & 0.86 & 65.99 & 1.00 & 135.80 \\
\hline 84 & MT-50 & 2019 & 31 & 86400 & 2280 & 1.42 & 68.74 & 1.25 & 135.61 \\
\hline 85 & MT-50 & 2019 & 32 & 86400 & 2383 & 0.89 & 66.59 & 1.23 & 137.08 \\
\hline 86 & MT-50 & 2019 & 33 & 86400 & 4158 & 1.01 & 67.13 & 1.40 & 137.38 \\
\hline 87 & MT-50 & 2019 & 34 & 86400 & 4102 & 1.31 & 65.69 & 1.42 & 132.50 \\
\hline 88 & MT-50 & 2019 & 35 & 86400 & 20204 & 1.21 & 66.34 & 1.35 & 138.76 \\
\hline 89 & MT-50 & 2019 & 36 & 86400 & 92646 & 0.99 & 66.48 & 1.22 & 139.55 \\
\hline 90 & MT-50 & 2019 & 37 & 86400 & 71077 & 1.32 & 67.17 & 1.62 & 139.59 \\
\hline 91 & MT-50 & 2019 & 38 & 86400 & 3631 & 1.16 & 65.43 & 1.61 & 127.67 \\
\hline 92 & MT-50 & 2019 & 39 & 86400 & 15246 & 1.35 & 65.70 & 1.40 & 135.68 \\
\hline 93 & MT-50 & 2019 & 40 & 86400 & 63255 & 0.97 & 64.60 & 0.97 & 126.92 \\
\hline 94 & MT-50 & 2019 & 41 & 86400 & 68228 & 1.60 & 66.74 & 1.39 & 133.89 \\
\hline 95 & MT-50 & 2019 & 42 & 86400 & 88927 & 1.34 & 64.15 & 1.32 & 132.11 \\
\hline 96 & MT-50 & 2019 & 43 & 86400 & 2208 & 1.22 & 67.62 & 1.04 & 135.31 \\
\hline 97 & MT-50 & 2019 & 44 & 86400 & 2384 & 1.37 & 67.81 & 1.21 & 134.04 \\
\hline 98 & MT-50 & 2019 & 45 & 86400 & 4439 & 0.93 & 76.78 & 1.20 & 187.07 \\
\hline 99 & MT-50 & 2019 & 46 & 86400 & 3549 & 1.84 & 67.44 & 1.44 & 135.23 \\
\hline 100 & EC2259 & 2019 & 49 & 11674 & 677 & 0.86 & 55.31 & 1.01 & 112.84 \\
\hline 101 & EC2259 & 2019 & 50 & 86400 & 4147 & 1.18 & 67.69 & 1.28 & 133.14 \\
\hline 102 & EC2259 & 2019 & 51 & 65300 & 2198 & 1.33 & 64.41 & 1.22 & 132.40 \\
\hline 103 & EC2259 & 2019 & 52 & 86400 & 28987 & 1.13 & 65.99 & 1.67 & 133.34 \\
\hline 104 & EC2259 & 2019 & 53 & 86400 & 3761 & 1.61 & 66.00 & 1.47 & 133.59 \\
\hline 105 & EC2259 & 2019 & 54 & 86400 & 63388 & 1.38 & 68.06 & 1.57 & 143.53 \\
\hline 106 & EC2259 & 2019 & 55 & 86400 & 4314 & 1.41 & 69.28 & 1.44 & 135.95 \\
\hline 107 & EC2259 & 2019 & 56 & 86400 & 36487 & 0.91 & 68.34 & 1.30 & 137.66 \\
\hline 108 & EC2259 & 2019 & 57 & 86400 & 42522 & 0.88 & 66.58 & 1.13 & 127.96 \\
\hline 109 & EC2259 & 2019 & 58 & 86400 & 2898 & 1.36 & 66.28 & 1.43 & 139.99 \\
\hline 110 & EC2259 & 2019 & 59 & 86400 & 54826 & 1.27 & 67.18 & 1.78 & 142.78 \\
\hline 111 & EC2259 & 2019 & 60 & 86400 & 2549 & 1.21 & 70.38 & 1.67 & 133.33 \\
\hline 112 & EC2259 & 2019 & 61 & 86400 & 3399 & 1.20 & 66.90 & 1.55 & 139.20 \\
\hline 113 & EC2259 & 2019 & 62 & 86400 & 3081 & 1.32 & 65.94 & 1.61 & 138.56 \\
\hline 114 & EC2259 & 2019 & 63 & 86400 & 2400 & 1.62 & 68.73 & 1.59 & 134.57 \\
\hline 115 & EC2259 & 2019 & 64 & 86400 & 2231 & 1.15 & 69.48 & 1.48 & 143.10 \\
\hline 116 & EC2259 & 2019 & 65 & 86400 & 48029 & 1.15 & 66.55 & 1.55 & 138.32 \\
\hline 117 & EC2259 & 2019 & 66 & 86400 & 58382 & 1.14 & 67.42 & 1.57 & 143.79 \\
\hline 118 & EC2259 & 2019 & 67 & 86400 & 2417 & 1.41 & 65.40 & 1.66 & 147.24 \\
\hline 119 & EC2259 & 2019 & 68 & 86400 & 2621 & 1.42 & 66.84 & 1.57 & 139.93 \\
\hline 120 & EC2259 & 2019 & 69 & 86400 & 2197 & 1.01 & 66.74 & 1.43 & 137.43 \\
\hline 121 & EC2259 & 2019 & 70 & 86400 & 2127 & 1.25 & 66.60 & 1.52 & 134.76 \\
\hline
\end{tabular}




\begin{tabular}{|c|c|c|c|c|c|c|c|c|c|}
\hline ID & Vessel & Year & DoY & Epochs (s) & Distance (m) & HPE (m) & HPL (m) & VPE (m) & VPL (m) \\
\hline 122 & EC2259 & 2019 & 71 & 86400 & 32176 & 0.94 & 69.34 & 1.30 & 131.16 \\
\hline 123 & EC2259 & 2019 & 72 & 86400 & 2102 & 1.13 & 69.52 & 1.48 & 140.76 \\
\hline 124 & EC2259 & 2019 & 73 & 86400 & 2394 & 0.90 & 66.15 & 1.21 & 143.07 \\
\hline 125 & EC2259 & 2019 & 74 & 86400 & 216181 & 1.26 & 68.29 & 2.02 & 145.58 \\
\hline 126 & EC2259 & 2019 & 75 & 86400 & 73649 & 1.29 & 70.09 & 1.70 & 135.42 \\
\hline 127 & EC2259 & 2019 & 76 & 86400 & 255143 & 1.23 & 69.48 & 1.88 & 138.77 \\
\hline 128 & EC2259 & 2019 & 77 & 86400 & 2988 & 0.84 & 64.86 & 1.15 & 122.16 \\
\hline 129 & EC2259 & 2019 & 78 & 86400 & 2956 & 1.71 & 65.61 & 1.63 & 124.22 \\
\hline 130 & EC2259 & 2019 & 79 & 86400 & 3299 & 0.81 & 67.43 & 1.22 & 126.44 \\
\hline 131 & EC2259 & 2019 & 80 & 86400 & 3804 & 1.87 & 70.36 & 1.56 & 132.43 \\
\hline 132 & EC2259 & 2019 & 81 & 86400 & 3789 & 1.48 & 69.78 & 1.29 & 125.60 \\
\hline 133 & EC2259 & 2019 & 82 & 86400 & 3925 & 0.93 & 68.40 & 1.35 & 127.46 \\
\hline 134 & EC2259 & 2019 & 94 & 47031 & 2101 & 2.44 & 73.03 & 1.68 & 151.88 \\
\hline 135 & EC2259 & 2019 & 95 & 86400 & 44151 & 1.60 & 67.12 & 1.57 & 152.49 \\
\hline 136 & EC2259 & 2019 & 96 & 86400 & 3608 & 1.73 & 67.83 & 1.59 & 146.40 \\
\hline 137 & EC2259 & 2019 & 97 & 86400 & 42836 & 1.09 & 65.57 & 1.43 & 149.28 \\
\hline 138 & EC2259 & 2019 & 98 & 86400 & 2119 & 0.84 & 65.24 & 1.28 & 139.19 \\
\hline 139 & EC2259 & 2019 & 99 & 86400 & 2293 & 0.88 & 69.87 & 1.30 & 148.18 \\
\hline 140 & EC2259 & 2019 & 100 & 86039 & 2640 & 1.49 & 67.13 & 1.71 & 139.99 \\
\hline 141 & EC2259 & 2019 & 101 & 86400 & 2399 & 1.49 & 65.80 & 1.30 & 138.89 \\
\hline 142 & EC2259 & 2019 & 102 & 86400 & 2590 & 1.35 & 66.75 & 1.36 & 144.61 \\
\hline 143 & EC2259 & 2019 & 103 & 86400 & 2445 & 1.52 & 66.80 & 1.78 & 145.03 \\
\hline 144 & EC2259 & 2019 & 104 & 86400 & 3239 & 1.18 & 67.00 & 1.48 & 147.58 \\
\hline 145 & EC2259 & 2019 & 105 & 86400 & 6411 & 1.17 & 69.55 & 1.65 & 142.85 \\
\hline 146 & EC2259 & 2019 & 106 & 86400 & 5972 & 1.03 & 66.64 & 1.38 & 144.06 \\
\hline 147 & EC2259 & 2019 & 107 & 86400 & 4826 & 1.22 & 66.18 & 2.08 & 147.15 \\
\hline 148 & EC2259 & 2019 & 108 & 86400 & 3367 & 0.97 & 64.83 & 1.07 & 145.49 \\
\hline 149 & EC2259 & 2019 & 109 & 86400 & 2570 & 0.93 & 68.21 & 1.27 & 164.88 \\
\hline 150 & EC2259 & 2019 & 110 & 86400 & 2015 & 1.00 & 66.19 & 1.30 & 148.41 \\
\hline 151 & EC2259 & 2019 & 111 & 86400 & 2082 & 0.99 & 67.18 & 1.59 & 143.89 \\
\hline
\end{tabular}

